\title{
L1CAM expression in endometrial carcinomas: an ENITEC collaboration study
}

Louis JM van der Putten ${ }^{\star}, 1$, Nicole CM Visser ${ }^{2}$, Koen van de Vijver ${ }^{3}$, Maria Santacana ${ }^{4}$, Peter Bronsert ${ }^{5}$, Johan Bulten ${ }^{2}$, Marc Hirschfeld ${ }^{6,7}$, Eva Colas ${ }^{8}$, Antonio Gil-Moreno ${ }^{8,9}$, Angel Garcia ${ }^{10}$, Gemma Mancebo ${ }^{11}$, Fransesc Alameda ${ }^{12}$, Jone Trovik $^{13}$, Reidun K Kopperud ${ }^{14,15}$, Jutta Huvila ${ }^{16}$, Stefanie Schrauwen ${ }^{17}$, Martin Koskas ${ }^{18}$, Francine Walker ${ }^{19}$, Vit Weinberger ${ }^{20}$, Lubos Minar ${ }^{20}$, Eva Jandakova ${ }^{21}$, Marc PLM Snijders ${ }^{22}$, Saskia van den Berg-van Erp ${ }^{23}$, Xavier Matias-Guiu ${ }^{4}$, Helga B Salvesen ${ }^{13}$, Frederic Amant ${ }^{17}$, Leon FAG Massuger ${ }^{1}$ and Johanna MA Pijnenborg ${ }^{24}$

Background: Identification of aggressive endometrioid endometrial carcinomas (EECs) and non-endometrioid carcinomas (NEECs) is essential to improve outcome. L1 cell adhesion molecule (L1CAM) expression is a strong prognostic marker in stage I EECs, but less is known about L1CAM expression in advanced-stage EECs and NEECs. This study analyses L1CAM expression in a clinically representative cohort of endometrial carcinomas.

Methods: The expression of L1CAM was immunohistochemically determined in 1199 endometrial carcinomas, treated at one of the European Network for Individualized Treatment of Endometrial Cancer (ENITEC) centres. Staining was considered positive when $>10 \%$ of the tumour cells expressed L1CAM. The association between L1CAM expression and several clincopathological characteristics and disease outcome was calculated.

Results: In all, L1CAM was expressed in 10\% of the 935 stage I EECs, 18\% of the 160 advanced stage EECs, and 75\% of the 104 NEECs. The expression of L1CAM was associated with advanced stage, nodal involvement, high tumour grade, non-endometrioid histology, lymphovascular space invasion, and distant recurrences in all cases, and with reduced survival in the EECs, but not in the NEECs.

Conclusions: The expression of L1CAM is a strong predictor of poor outcome in EECs, but not NEECs. It is strongly associated with non-endometrioid histology and distant spread, and could improve the postoperative selection of high-risk endometrial carcinomas. The value of L1CAM expression in the preoperative selection of high-risk endometrial carcinomas should be studied.

Endometrial carcinoma is the most common gynaecological malignancy in developed countries (Siegel et al, 2012). These carcinomas can be histologically classified as either endometrioid endometrial carcinomas (EECs) or non-endometrioid endometrial carcinomas (NEECs) (Lax, 2004; Matias-Guiu and Prat, 2013). In general, EECs have a favourable prognosis, and are characterised by expression of the oestrogen and progesterone receptors, microsatellite instability, and PTEN, KRAS, PIK3CA, and CTNNB1 mutations. The most common NEECs have serous or clear cell histology, and a worse prognosis. They are characterised by TP53 mutations, and PTEN and PIK3CA mutations, respectively. Less common carcinomas with non-endometrioid histology are those with undifferentiated histology, characterised by microsatellite instability, those with mucinous histology, with a prognosis and molecular characterisation similar to EECs, and the carcinosarcomas. However, a substantial number of endometrial carcinomas do not fit within this dualistic model, and have mixed histology or hybrid molecular and histological characteristics, making diagnosis challenging (Matias-Guiu and Prat, 2013). After primary surgery, adjuvant treatment is recommended based on the presence of predictors of poor outcome, most importantly FIGO stage. In addition, the prognosis is related to histological type, tumour grade, myometrial invasion, lymphovascular space invasion (LVSI), and the age of the patient (Amant et al, 2015). More recently, a new subdivision into four subgroups, based on the molecular profile, was proposed by The Cancer Genome Atlas

*Correspondence: Dr LJM van der Putten; E-mail: louis.vanderputten@radboudumc.nl

Received 26 April 2016; revised 8 July 2016; accepted 12 July 2016; published online 9 August 2016

(c) 2016 Cancer Research UK. All rights reserved 0007-0920/16 
Research network (Cancer Genome Atlas Research Network et al, 2013). However, these data have not been incorporated in clinical practice yet. In addition, several immunohistochemical markers have been shown to be associated with poor outcome. Expression of the transmembrane L1 cell adhesion molecule (L1CAM) seems to be one of the most powerful ones described to date. The L1CAM plays an important role in neurogenesis, but has been associated with poor outcome in various cancer types (Fogel et al, 2003; Allory et al, 2005; Boo et al, 2007; Schroder et al, 2009; Tischler et al, 2011; Tsutsumi et al, 2011; Bondong et al, 2012; Schafer and Frotscher, 2012; Wang et al, 2013). Two large studies have shown a strong association between L1CAM expression in stage I EEC and poor disease outcome (Zeimet et al, 2013; Bosse et al, 2014). However, there was a wide variation in both the percentage of cases expressing L1CAM and the strength of the association between L1CAM and disease outcome found by these studies. More recently, several smaller studies have highlighted the association between L1CAM expression and poor disease outcome in advanced-stage EECs and NEECs, as well as a strong association between L1CAM expression and non-endometrioid histology (Dellinger et al, 2016; Geels et al, 2016; Van Gool et al, 2016). However, these studies have limited clinical applicability because neither of these studies analysed the subgroups separately, and the number of included advanced-stage EECs and NEECs is still limited. In addition, Dellinger et al (2016) used mRNA L1CAM expression with a different cutoff than the other studies that limits the comparability.

The aim of the current study is therefore to analyse the value of immunohistochemical L1CAM expression in a large, clinically representative cohort of endometrial carcinomas, including substantial numbers of all histological types and FIGO stages.

\section{MATERIALS AND METHODS}

Patients. This study was performed within the European Network for Individualized Treatment of Endometrial Cancer (ENITEC), a European Society of Gynecological Oncology (ESGO) consortium aiming to improve and individualise treatment of women with uterine cancers by sharing expertise. All ENITEC members were invited to participate in this study and to include patients treated for stage I EEC (a maximum of 150 cases per centre), stage II-IV EEC, or NEEC. Cases with any non-endometrioid component were included in the NEEC group, except for the mucinous carcinomas that were included in the EEC groups as their characteristics and prognosis are similar to that of endometrioid carcinomas (Lax, 2004). Only cases diagnosed by an expert gynecological pathologist, with complete data on treatment and pathology, and at least 36 months of follow-up were included. Clinical and pathological data were recorded from the patient files into a database, including patient age, date of diagnosis, surgical treatment (including lymphadenectomy and omentectomy), tumour histology and grade, myometrial invasion, cervical invasion, LVSI, FIGO stage, adjuvant treatment (including radiotherapy, chemotherapy and chemoradiation), residual disease, recurrent disease, and death.

Tissue and staining. One representative slide was selected per case. Blank $4 \mu \mathrm{m}$ sections, cut from the corresponding formalinfixed, paraffin-embedded tissue blocks, on Superfrost slides were sent to the Radboud University Medical Center. A haematoxylin and eosin and an immunohistochemically stained L1CAM slide were made for every case. Immunohistochemical staining was performed in semiautomatic staining devices using an optimised version of the previously described staining protocol (Fogel et al, 2014). In short, after EDTA antigen retrieval and blocking of endogenous peroxidase with hydrogen peroxide, slides were incubated with 1:100 diluted L1CAM antibody (purified antiCD171 (L1) antibody clone 14.10, Biolegend, San Diego, CA, USA). They were subsequently incubated with PowerVision + Poly-HRP and visualised with PowerVision DAB substrate solution (Leica Biosystems, Buffalo Grove, IL, USA). Finally, the slides were counterstained with haematoxylin, dehydrated, and mounted. Staining of the nerves was used as internal positive control.

Scoring. All slides were scored twice, by independent pathologists. First by NCM Visser or K van de Vijver, and subsequently by M Santacana, P Bronsert or J Bulten. They were blinded for clinical and pathological data, as well as each other's scores. They were asked to score the number of stained tumour cells as $0 \%, 1-10 \%$ $11-50 \%$, or $51-100 \%$, and cases were considered to express L1CAM when one or both pathologists considered $>10 \%$ of the tumour cells to be stained, in accordance with the previously described cutoff (Zeimet et al, 2013; Bosse et al, 2014; Geels et al, 2016). Cohen's $\kappa$ was calculated for L1CAM expression as a dichotomous variable (either $\leqslant 10 \%$ or $>10 \%$ ). In case of large discrepancies (i.e., if one pathologist scored $0 \%$ and the other $11-100 \%$, or if one pathologist scored $1-10 \%$ and the other $51-100 \%$ ) the slides were reviewed by a third pathologist who did not score the slide initially (either NCM Visser or J Bulten).

Statistical analysis. Clinicopathological differences between L1CAM-positive and -negative cases were compared using the $\chi^{2}$ and Fisher's exact tests for categorical variables and the MannWhitney $U$-test for continuous variables, and corresponding $P$-values are shown in Tables 1-4.

The association between L1CAM expression and other known risk factors expressed as an odds ratio (OR) and corresponding 95\% confidence interval (95\% CI) was calculated using univariate logistic regression analysis. These risk factors were deep myometrial invasion, patient age over 60 years, LVSI, non-endometrioid (except mucinous) histology, advanced FIGO stage, and nodal involvement.

The Kaplan-Meier curves of 10-year disease-free and overall survival were generated for the stage I EEC, stage II-IV EEC, and NEEC subgroups. The corresponding hazard ratio (HR) and 95\% CI was calculated using Cox regression analysis. For stage I EECs a multivariate analysis was performed including covariates that were significantly associated with outcome in the univariate analysis. Sample size calculation accounted only for multivariate Cox regression analysis of the stage I EECs.

Statistical differences were considered significant at a two-sided $P$-value of $\leqslant 0.05$. SPSS version 22 (SPSS IBM, New York, NY, USA) statistical software was used to perform the statistical analyses.

Ethical approval. The study was approved by the institutional review board (IRB) of all participating centres.

\section{RESULTS}

L1CAM in endometrial carcinomas. There were 1199 cases included from 10 European centres, including 935 stage I EECs, 160 stage II-IV EECs, and 104 NEECs. The L1CAM was expressed in $200(17 \%)$ cases, and was scored with a $\kappa$ of 0.82 . Table 1 shows demographic and tumour characteristics of all cases and a comparison between the L1CAM-negative and -positive cases. These two groups were significantly different concerning demographics, treatment, tumour characteristics, and disease outcome.

In univariate regression analysis, L1CAM expression was significantly associated with advanced stage (OR 5.1, 95\% CI 3.5-7.3), nodal involvement (OR 5.0, 95\% CI 3.2-7.7), and non-endometrioid histology (OR 24.0, 95\% CI 14.8-38.8). 
Table 1. Comparison of the clinical and pathologic characteristics and disease outcome of all included carcinomas with respect to the L1CAM expression

\begin{tabular}{|c|c|c|c|c|}
\hline & All & L1CAM - & L1CAM + & $P^{a}$ \\
\hline Number of patients & 1199 & 999 (83\%) & $200(17 \%)$ & \\
\hline Median age (years) & 64 (range 31-93) & 63 (range 31-93) & 69 (range 39-93) & $<0.01$ \\
\hline Median follow-up ${ }^{\mathbf{b}}$ (months) & 62 (range 0-229) & $64(1-229)$ & 50 (range 0-185) & $<0.01$ \\
\hline $\begin{array}{l}\text { Treatment } \\
\text { Lymphadenectomy } \\
\text { Radiotherapy } \\
\text { Chemotherapy }\end{array}$ & $\begin{array}{l}795(66 \%) \\
563(47 \%) \\
123(10 \%)\end{array}$ & $\begin{array}{c}645(65 \%) \\
467(47 \%) \\
72(7 \%)\end{array}$ & $\begin{array}{l}150(75 \%) \\
96(48 \%) \\
51(26 \%)\end{array}$ & $\begin{array}{l}<0.01 \\
0.86 \\
<0.01\end{array}$ \\
\hline $\begin{array}{l}\text { Histology } \\
\text { Endometrioid } \\
\text { Non-endometrioid }\end{array}$ & $\begin{array}{c}1095 \text { (91\%) } \\
104(9 \%)\end{array}$ & $\begin{array}{c}973(97 \%) \\
26(3 \%)\end{array}$ & $\begin{array}{l}122(61 \%) \\
78(39 \%)\end{array}$ & $<0.01$ \\
\hline $\begin{array}{l}\text { Myometrial invasion } \\
\quad<1 / 2 \\
\geqslant 1 / 2\end{array}$ & $\begin{array}{l}746(62 \%) \\
453(38 \%)\end{array}$ & $\begin{array}{l}656(66 \%) \\
343(34 \%)\end{array}$ & $\begin{array}{c}90(45 \%) \\
110(55 \%)\end{array}$ & $<0.01$ \\
\hline $\begin{array}{l}\text { LVSI } \\
\text { No } \\
\text { Yes } \\
\text { Unknown }\end{array}$ & $\begin{array}{c}813(68 \%) \\
162(14 \%) \\
224\end{array}$ & $\begin{array}{c}723(88 \%) \\
101(12 \%) \\
175\end{array}$ & $\begin{array}{c}90(60 \%) \\
61(41 \%) \\
49\end{array}$ & $<0.01$ \\
\hline $\begin{array}{l}\text { Outcome } \\
\text { Residual disease } \\
\text { Recurrence } \\
\text { Locoregional } \\
\text { Distant } \\
\text { Deceased } \\
\text { Endometrial cancer }\end{array}$ & $\begin{array}{c}40(3 \%) \\
158(13 \%) \\
76(7 \%) \\
98(8 \%) \\
171(14 \%) \\
99(8 \%)\end{array}$ & $\begin{array}{c}15(2 \%) \\
100(10 \%) \\
57(6 \%) \\
53(5 \%) \\
104(10 \%) \\
48(5 \%)\end{array}$ & $\begin{array}{l}25(12.5 \%) \\
58(33 \%) \\
19(11 \%) \\
45(26 \%) \\
67(34 \%) \\
51(26 \%)\end{array}$ & $\begin{array}{r}<0.01 \\
<0.01 \\
0.02 \\
<0.01 \\
<0.01 \\
<0.01\end{array}$ \\
\hline
\end{tabular}

L1CAM in stage I endometrioid endometrial carcinomas. Patient and tumour characteristics of all stage I EEC cases ( $n=935$, including 4 mucinous carcinomas) with respect to L1CAM expression are shown in Table 2. The L1CAM was expressed in $93(10 \%)$ cases. These patients were older, had a higher tumour grade and LVSI, and more often presented with distant recurrence and disease-related mortality.

In univariate regression analysis, L1CAM expression was significantly associated with grade 3 histology (OR 4.1, 95\% CI 2.5-6.8) and LVSI (OR 2.9, 95\% CI 1.5-5.6), but not with deep myometrial invasion.

L1CAM in advanced-stage endometrioid endometrial carcinomas. Patient and tumour characteristics of all advanced-stage EEC cases ( $n=160$, including 5 mucinous carcinomas) with respect to L1CAM expression are shown in Table 3. The expression of L1CAM was present in $28(18 \%)$ cases. These cases had a higher tumour grade, a more advanced FIGO stage, and more often presented with distant recurrence and disease-related mortality.

In univariate regression analysis, L1CAM expression was significantly associated with the presence of nodal disease (OR 4.1, 95\% CI 1.5-11.5) and LVSI (OR 3.0, 95\% CI 1.1-8.0).

L1CAM in non-endometrioid carcinomas. Patient and tumour characteristics of all NEEC cases $(n=104)$ with respect to L1CAM expression are shown in Table 4. The expression of L1CAM was present in $78(75 \%)$ cases, and varied between the subgroups: $77 \%$ of the serous carcinomas, $82 \%$ of the clear cell carcinomas, $64 \%$ of the carcinosarcomas, and $57 \%$ of the undifferentiated carcinomas expressed L1CAM. Patients with L1CAM expression were older, more often had LVSI, and more often presented with distant recurrences and disease-related mortality.

In univariate regression analysis, L1CAM expression was significantly associated with the presence of LVSI (OR 4.6, 95\% CI 1.5-14.1).

L1CAM expression and survival. The 10-year disease-free and overall survival Kaplan-Meier plots are shown in Figure 1. Corresponding HRs are shown in Table 5.

Multivariate analysis of the stage I EEC cases showed that expression of L1CAM is a strong and independent predictor of both reduced disease-free survival and overall survival, along with several known prognostic markers. Patient age of $>60$ years was the strongest predictor of reduced overall survival, but not of reduced disease-specific survival (data not shown).

The expression of L1CAM and the presence of LVSI in advanced-stage EEC cases were significantly associated with reduced disease-free, and overall survival in univariate analysis. Grade 3 histology and deep myometrial invasion predicted a reduced overall survival as well, but the myometrial invasion HR had a very wide CI.

Analysis of the NEEC cases showed that L1CAM expression is not associated with reduced disease-free and overall survival. Patient age of $>60$ years and advanced FIGO stage were associated 
Table 2. Comparison of the clinical and pathologic characteristics as well as disease outcome of stage I endometrioid endometrial carcinomas with respect to L1CAM expression

\begin{tabular}{|c|c|c|c|c|}
\hline & All & L1CAM - & L1CAM + & $P^{a}$ \\
\hline Number of patients & 935 & 842 (90\%) & $93(10 \%)$ & \\
\hline Median age (years) & 63 (range 32-93) & 63 (range 32-91) & 67 (range 39-93) & $<0.01$ \\
\hline Median follow-up ${ }^{\mathbf{b}}$ (months) & 64 (range 1-210) & 65 (range 1-210) & 55 (range 6-185) & $<0.01$ \\
\hline $\begin{array}{l}\text { Treatment } \\
\text { Lymphadenectomy } \\
\text { Radiotherapy } \\
\text { VBT } \\
\text { EBRT + / - VBT } \\
\text { Chemotherapy }\end{array}$ & $\begin{array}{c}586(63 \%) \\
400(43 \%) \\
206(22 \%) \\
190(20 \%) \\
36(4 \%)\end{array}$ & $\begin{array}{l}519(62 \%) \\
359(43 \%) \\
189(23 \%) \\
166(20 \%) \\
31(4 \%)\end{array}$ & $\begin{array}{c}67(72 \%) \\
41(44 \%) \\
17(18 \%) \\
24(26 \%) \\
5(5 \%)\end{array}$ & $\begin{array}{l}0.05 \\
0.79 \\
0.42\end{array}$ \\
\hline $\begin{array}{c}\text { Grade } \\
1 \\
2 \\
3\end{array}$ & $\begin{array}{l}442(47 \%) \\
389(42 \%) \\
104(11 \%)\end{array}$ & $\begin{array}{c}418(50 \%) \\
348(41 \%) \\
76(9 \%)\end{array}$ & $\begin{array}{l}24(26 \%) \\
41(44 \%) \\
28(30 \%)\end{array}$ & $<0.01$ \\
\hline $\begin{array}{l}\text { Myometrial invasion } \\
\quad<1 / 2 \\
\geqslant 1 / 2\end{array}$ & $\begin{array}{l}664(71 \%) \\
271(29 \%)\end{array}$ & $\begin{array}{l}604(72 \%) \\
238(28 \%)\end{array}$ & $\begin{array}{l}60(65 \%) \\
33(36 \%)\end{array}$ & 0.15 \\
\hline $\begin{array}{l}\text { LVSI } \\
\text { No } \\
\text { Yes } \\
\text { Unknown }\end{array}$ & $\begin{array}{c}703(91 \%) \\
67(9 \%) \\
165\end{array}$ & $\begin{array}{c}645(92 \%) \\
53(8 \%) \\
144\end{array}$ & $\begin{array}{c}58(81 \%) \\
14(19 \%) \\
21\end{array}$ & $<0.01$ \\
\hline $\begin{array}{l}\text { Outcome } \\
\text { Recurrence } \\
\text { Locoregional } \\
\text { Distant } \\
\text { Deceased } \\
\text { Endometrial cancer }\end{array}$ & $\begin{array}{l}85(9 \%) \\
48(5 \%) \\
42(5 \%) \\
88(9 \%) \\
37(4 \%)\end{array}$ & $\begin{array}{l}66(8 \%) \\
41(5 \%) \\
29(3 \%) \\
69(8 \%) \\
26(3 \%)\end{array}$ & $\begin{array}{c}19 \text { (20\%) } \\
7(8 \%) \\
13(14 \%) \\
19(20 \%) \\
11(12 \%)\end{array}$ & $\begin{array}{c}<0.01 \\
0.27 \\
<0.01 \\
<0.01 \\
<0.01\end{array}$ \\
\hline
\end{tabular}

with reduced disease-free survival, and the presence of LVSI and advanced FIGO stage were associated with reduced overall survival.

\section{DISCUSSION}

This large, well-documented series of 1199 endometrial carcinomas shows a strong association between L1CAM expression and poor outcome in stage I EECs and advanced-stage EECs, but not in NEECs. Moreover, L1CAM expression was shown to be associated with the presence of nodal disease, grade 3 histology, LVSI, and distant disease recurrences, but especially with non-endometrioid histology.

Prognostic value of L1CAM expression in stage I endometrioid carcinomas. Two large studies have described the prognostic value of L1CAM expression in stage I EECs. Zeimet et al (2013) found L1CAM expression in $17 \%$ of the cases, with HRs of 16.33 for recurrence and 15.01 for death. The PORTEC group found L1CAM expression in 7\%, with HRs of 2.55 for pelvic recurrence, 3.48 for distant recurrence, and 2.05 for death (Bosse et al, 2014). In comparison, we found L1CAM expression in $10 \%$ of the stage I EECs, with HRs of 2.3 for recurrences, 2.8 for distant recurrences, and 2.4 for death.

The number of lymphadenectomies performed in our study was slightly higher than in the Zeimet study. The PORTEC study does not mention the exact number of lymphadenectomies, but it is described that routine lymphadenectomies were not performed, and only suspicious nodes were removed. Patients in our study received radiotherapy, especially external beam radiotherapy, more often than patients in the Zeimet study, but less often than those in the PORTEC study. Patients in the PORTEC study more often had a low-grade tumour and deep myometrial invasion that was related to the inclusion criteria of the study. In the Zeimet study LVSI was present in a large number of carcinomas compared with both our study and the PORTEC study.

It was hypothesised that a lower number of included grade 1 cases might explain the higher number of L1CAM-positive cases in the Zeimet study (Bosse et al, 2014). Although we show a strong association between L1CAM expression and grade 3 histology, our study included even fewer grade 1 cases, making it unlikely that this explains the difference in L1CAM expression. As we show a strong association between the presence of L1CAM expression and LVSI, it is possible that the high prevalence of LVSI in the Zeimet study is responsible for the high number of L1CAM-positive cases, and the exceptionally strong association between L1CAM expression and poor outcome they describe.

Several smaller studies included stage I EECs in addition to advanced-stage EECs and NEECs. Unfortunately, both Van Gool et al (2016) and Geels et al (2016) did not analyse the value of L1CAM expression specifically in the stage I EECs, making it impossible to compare our findings with these studies. Interestingly, Dellinger et al (2016) included a sizeable amount of stage I EECs and analysed the association between mRNA expression of L1CAM and prognosis, but were not able to validate the strong prognostic value of L1CAM expression. This might be explained by the fact that they considered all cases with an mRNA L1CAM expression above the median to be positive, resulting in a much higher proportion of L1CAM-positive cases in their study compared with other L1CAM studies.

Prognostic value of L1CAM expression in advanced-stage endometrioid carcinomas and non-endometrioid carcinomas. Several previous studies described the prognostic value of L1CAM expression in advanced-stage EECs and NEECs. Fogel et al (2003) described L1CAM expression in all of the 10 included FIGO stage III and IV cases, but the histology was not mentioned, and 3 previous studies described L1CAM expression in $73 \%$ of the 15 , 
Table 3. Comparison of the clinical and pathologic characteristics as well as disease outcome of advanced-stage endometrioid endometrial carcinoma cases with respect to L1CAM expression

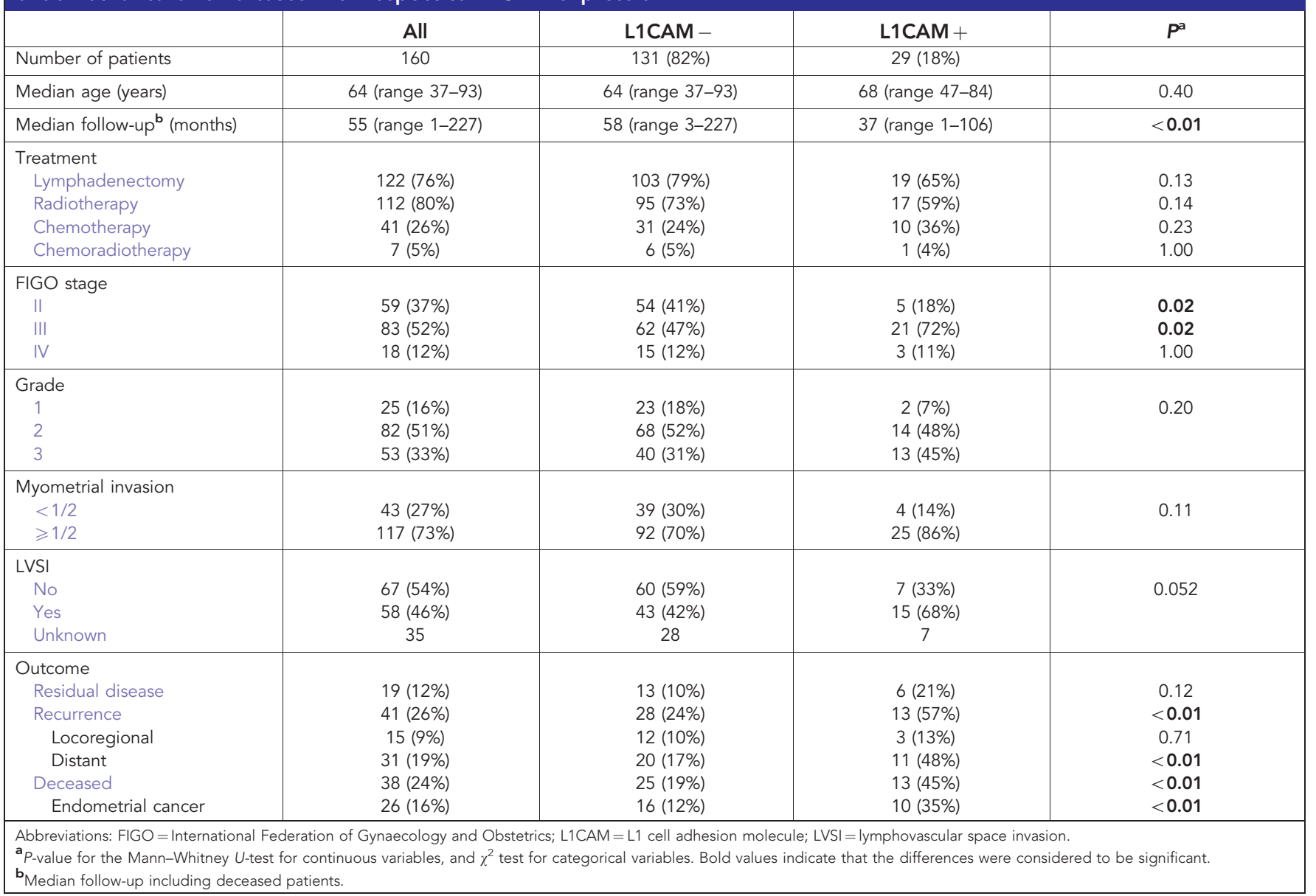

$58 \%$ of the 12 , and $55 \%$ of the 20 included NEEC cases (Zeimet et al, 2013; Bosse et al, 2014). We found L1CAM expression in $75 \%$ of the 104 NEEC cases.

Three studies included both advanced-stage EECs and NEECs and described the association between L1CAM expression and clinicopathological variables, as well as between L1CAM expression and outcome (Dellinger et al, 2016; Geels et al, 2016; Van Gool et al, 2016). Geels et al (2016) found an association between L1CAM expression and high tumour grade and LVSI, Dellinger et al (2016) between L1CAM expression and advanced FIGO stage, non-endometrioid histology, high tumour grade, deep myometrial invasion, and nodal spread, and Van Gool et al (2016) between L1CAM expression and non-endometrioid histology and high tumour grade, but not FIGO stage, depth of myometrial invasion, and LVSI. In comparison, we found an association between L1CAM expression and advanced FIGO stage, non-endometrioid histology, high tumour grade, LVSI, and nodal spread. We found these associations in all three subgroups, but unfortunately neither of these studies analysed the association between L1CAM and clinicopathological variables within the subgroups.

In addition, neither of these studies analysed the disease-free and overall survival separately in the advanced-stage EECs and NEECs. Our subgroup analyses have shown that there is indeed a strong association between L1CAM expression and poor outcome in the advanced-stage EECs, but not in the NEECs, possibly because the presence of non-endometrioid histology itself is a strong marker of poor prognosis, and the majority were L1CAM positive. The fact that previous studies have combined the advanced-stage EECs and the NEECs in the high-risk carcinoma group might therefore have influenced their results, and additional studies are required to validate the prognostic value of L1CAM expression separately in the advanced-stage EECs and the NEECs.

This study shows that there is a very strong association between L1CAM expression and the presence of non-endometrioid histology. Up until now, p53 expression has been used to identify NEECs, and whereas p53 is frequently expressed in serous carcinomas, it does not play an important role in other NEECs (Lax, 2004). Previous studies reported p53 expression in $62-67 \%$ of all NEECs, whereas we found L1CAM expression in $75 \%$ of the NEECs, including $77 \%$ of the serous and $82 \%$ of the clear cell carcinomas (Engelsen et al, 2006; Van Gool et al, 2016). Based on these findings L1CAM expression appears to be the most powerful marker to identify NEECs described to date.

Interestingly, Van Gool et al (2016) did not find an association between L1CAM expression with a cutoff of $10 \%$ and poor outcome in their cohort of high-risk carcinomas, including highrisk stage I EECs, but did find this association when using a cutoff of $50 \%$. We however did find an association between L1CAM expression with a cutoff of $10 \%$ and poor outcome in the advanced-stage EECs and NEECs, and preliminary analyses did not show a major advantage of using a higher cutoff (data not shown). Using one cutoff in all subgroups would be preferable, because having to determine the tumour histology, tumour grade, and the depth of myometrial invasion before choosing the L1CAM cutoff would greatly limit the clinical applicability.

It has to be noted that mixed carcinomas were included in the NEEC group of our study, and pure non-endometrioid histology was more common in the L1CAM-positive cases. There is a 
Table 4. Comparison of the clinical and pathologic characteristics as well as disease outcome of the non-endometrioid carcinoma cases with respect to L1CAM expression

\begin{tabular}{|c|c|c|c|c|}
\hline & All & L1CAM - & L1CAM + & $P^{a}$ \\
\hline Number of patients & 104 & $26(25 \%)$ & $78(75 \%)$ & \\
\hline Median age (years) & 69 (range 31-88) & 64 (range 31-83) & 70 (range 49-88) & $<0.01$ \\
\hline Median follow-up b (months) & 46 (range $0-229$ ) & 52 (range 2-229) & 45 (range 0-129) & 0.15 \\
\hline $\begin{array}{l}\text { Treatment } \\
\text { Lymphadenectomy } \\
\text { Radiotherapy } \\
\text { Chemotherapy }\end{array}$ & $\begin{array}{l}87(84 \%) \\
51(49 \%) \\
46(44 \%)\end{array}$ & $\begin{array}{l}23(89 \%) \\
13(50 \%) \\
10(39 \%)\end{array}$ & $\begin{array}{l}64(82 \%) \\
38(49 \%) \\
36(46 \%)\end{array}$ & $\begin{array}{l}0.56 \\
0.91 \\
0.50\end{array}$ \\
\hline $\begin{array}{l}\text { FIGO stage } \\
\text { I } \\
\text { II } \\
\text { III } \\
\text { IV }\end{array}$ & $\begin{array}{l}30(39 \%) \\
15(14 \%) \\
42(40 \%) \\
17(16 \%)\end{array}$ & $\begin{array}{c}7(27 \%) \\
4(15 \%) \\
14(54 \%) \\
1(4 \%)\end{array}$ & $\begin{array}{l}23(30 \%) \\
11(14 \%) \\
28(36 \%) \\
16(21 \%)\end{array}$ & $\begin{array}{l}0.73 \\
1.00 \\
0.11 \\
0.06\end{array}$ \\
\hline $\begin{array}{l}\text { Histology } \\
\text { Pure NEEC } \\
\text { Mixed EEC/NEEC } \\
\text { Primary NEEC component } \\
\text { Serous } \\
\text { Clear cell } \\
\text { Carcinosarcoma } \\
\text { Undifferentiated }\end{array}$ & $\begin{array}{l}76(73 \%) \\
28(27 \%) \\
61(59 \%) \\
22(21 \%) \\
14(14 \%) \\
7(7 \%)\end{array}$ & $\begin{array}{l}17(65 \%) \\
9(35 \%) \\
14(54 \%) \\
4(15 \%) \\
5(19 \%) \\
3(12 \%)\end{array}$ & $\begin{array}{l}59(76 \%) \\
19(24 \%) \\
47(60 \%) \\
18(23 \%) \\
9(12 \%) \\
4(5 \%)\end{array}$ & $\begin{array}{l} \\
0.57 \\
0.58 \\
0.33 \\
0.36\end{array}$ \\
\hline $\begin{array}{l}\text { Myometrial invasion } \\
<1 / 2 \\
\geqslant 1 / 2\end{array}$ & $\begin{array}{l}39(38 \%) \\
65 \text { (63\%) }\end{array}$ & $\begin{array}{l}13(50 \%) \\
13(50 \%)\end{array}$ & $\begin{array}{l}26(33 \%) \\
52(67 \%)\end{array}$ & 0.13 \\
\hline $\begin{array}{l}\text { LVSI } \\
\text { No } \\
\text { Yes } \\
\text { Unknown }\end{array}$ & $\begin{array}{c}43(54 \%) \\
37(46 \%) \\
24\end{array}$ & $\begin{array}{c}18(78 \%) \\
5(22 \%) \\
3\end{array}$ & $\begin{array}{c}25(44 \%) \\
32(56 \%) \\
21\end{array}$ & $<0.01$ \\
\hline $\begin{array}{l}\text { Outcome } \\
\text { Residual disease } \\
\text { Recurrence } \\
\text { Locoregional } \\
\text { Distant } \\
\text { Deceased } \\
\text { Endometrial cancer }\end{array}$ & $\begin{array}{l}21(20 \%) \\
32(39 \%) \\
13(16 \%) \\
25(30 \%) \\
45(43 \%) \\
36(35 \%)\end{array}$ & $\begin{array}{c}2(8 \%) \\
6(25 \%) \\
4(17 \%) \\
4(17 \%) \\
10(39 \%) \\
6(23 \%)\end{array}$ & $\begin{array}{c}19(24 \%) \\
26(44 \%) \\
9(15 \%) \\
21(36 \%) \\
35(45 \%) \\
30(39 \%)\end{array}$ & $\begin{array}{l}0.09 \\
0.14 \\
1.00 \\
0.12 \\
0.57 \\
0.23\end{array}$ \\
\hline
\end{tabular}

possibility that mixed cases with a large endometrioid component were considered L1CAM negative in our study, even though L1CAM was expressed in over $10 \%$ of the non-endometrioid component.

Relationship between these findings and the function of L1CAM. The L1CAM was shown to have several extracellular and intracellular functions in cancer, both in an intact and cleaved form, as it has an influence on cell migration, cell survival, angiogenesis, and tumour progression (Mechtersheimer et al, 2001; Shtutman et al, 2006; Sebens Muerkoster et al, 2007; Stoeck et al, 2007; Gast et al, 2008a, b; Friedli et al, 2009). It is known that epithelial-to-mesenchymal transition (EMT) plays an important role in endometrial cancer invasion and metastasis (Colas et al, 2012). Several studies suggest that L1CAM expression induces an EMT-like transition that increases the metastatic potential, without altering the invasive capabilities. Comparable to EMT, expression of L1CAM was shown to be TGF $\beta$ and Slug dependent (Geismann et al, 2009; Huszar et al, 2010). Moreover, several studies have shown that intracellular L1CAM signalling activates NF- $\kappa$ B that was shown to be essential for EMT and metastasis of breast cancer (Huber et al, 2004; Gavert et al, 2010; Kiefel et al, 2012). In colorectal cancer cell lines, L1CAM expression was shown to increase cell motility and liver metastasis, without changes in expression of epithelial or mesenchymal markers.
Introduction of major EMT regulators changed expression of epithelial and mesenchymal markers, but did not increase the metastatic potential (Gavert et al, 2011). Many clinical studies have shown that there is a strong association between L1CAM expression and metastasis in various cancer types (Allory et al, 2005; Boo et al, 2007; Schroder et al, 2009; Tischler et al, 2011; Tsutsumi et al, 2011; Bondong et al, 2012; Wang et al, 2013). The current study shows a comparable association between L1CAM expression and advanced stage, lymph node involvement, and metastasis in both EECs and NEECs. Interestingly, there was no strong association between L1CAM expression and myometrial and cervical invasion, and although it was not scored separately in our study, the pathologists did not notice a clear localisation of L1CAM at the invasive front of the carcinomas. These findings are in accordance with the hypothesis that L1CAM induces EMT-like changes, but only plays a role in metastasis, and not invasion.

However, several previous studies analysing the association between L1CAM expression and clinicopathological variables present conflicting results concerning whether or not there is an association between L1CAM expression and the presence of LVSI, deep myometrial invasion, and cervical invasion (Zeimet et al, 2013; Bosse et al, 2014; Dellinger et al, 2016; Geels et al, 2016; Van Gool et al, 2016). Future studies focussing on the function of L1CAM will likely provide more insight into the possible association between L1CAM and these processes of invasion and metastasis. 

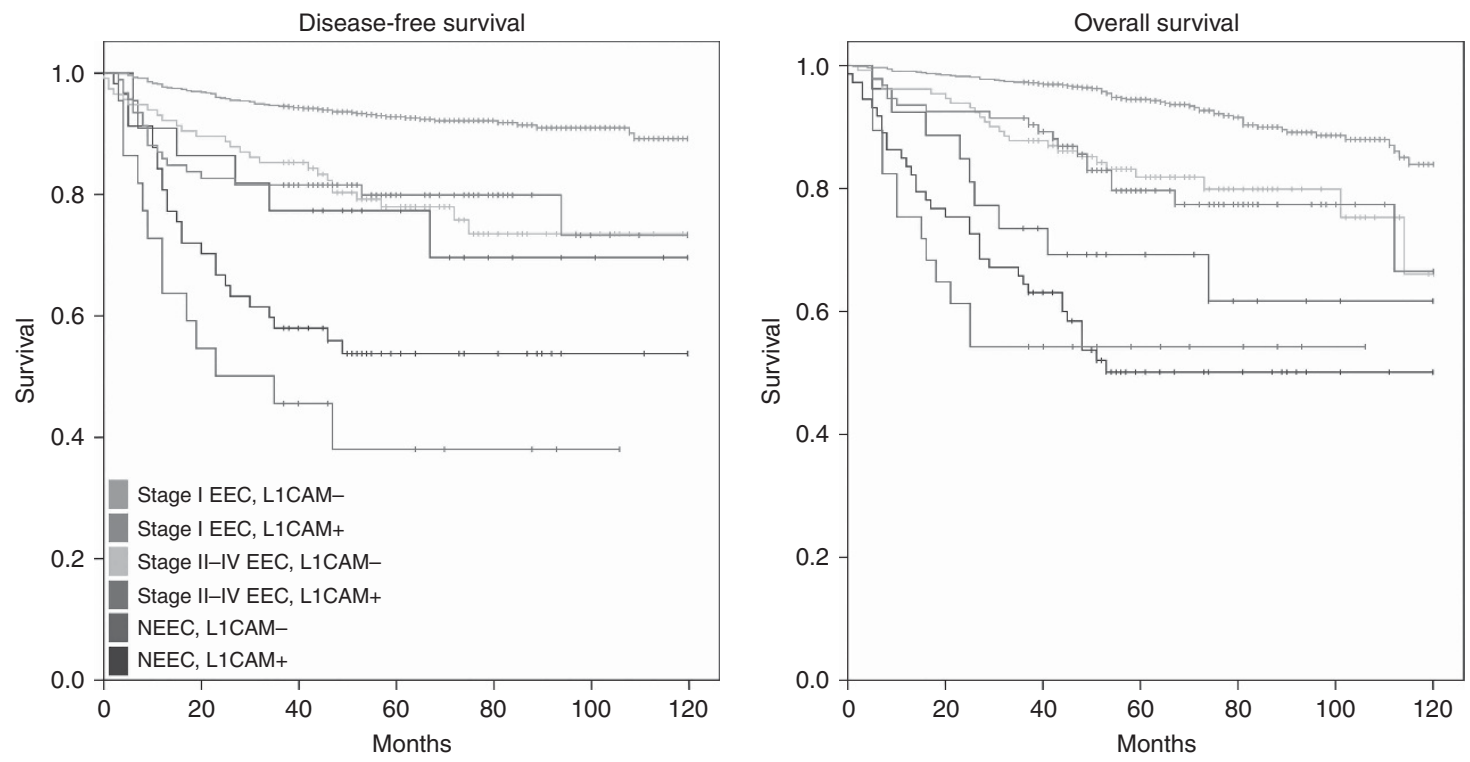

Figure 1. Kaplan-Meier plots of the 10-year disease-free and overall survival of the stage I endometrioid, advanced-stage endometrioid, and non-endometrioid cases with respect to L1CAM expression (a full colour version of this figure appears online).

Table 5. Results of the Cox regression analysis, depicting the association between several risk factors and outcome

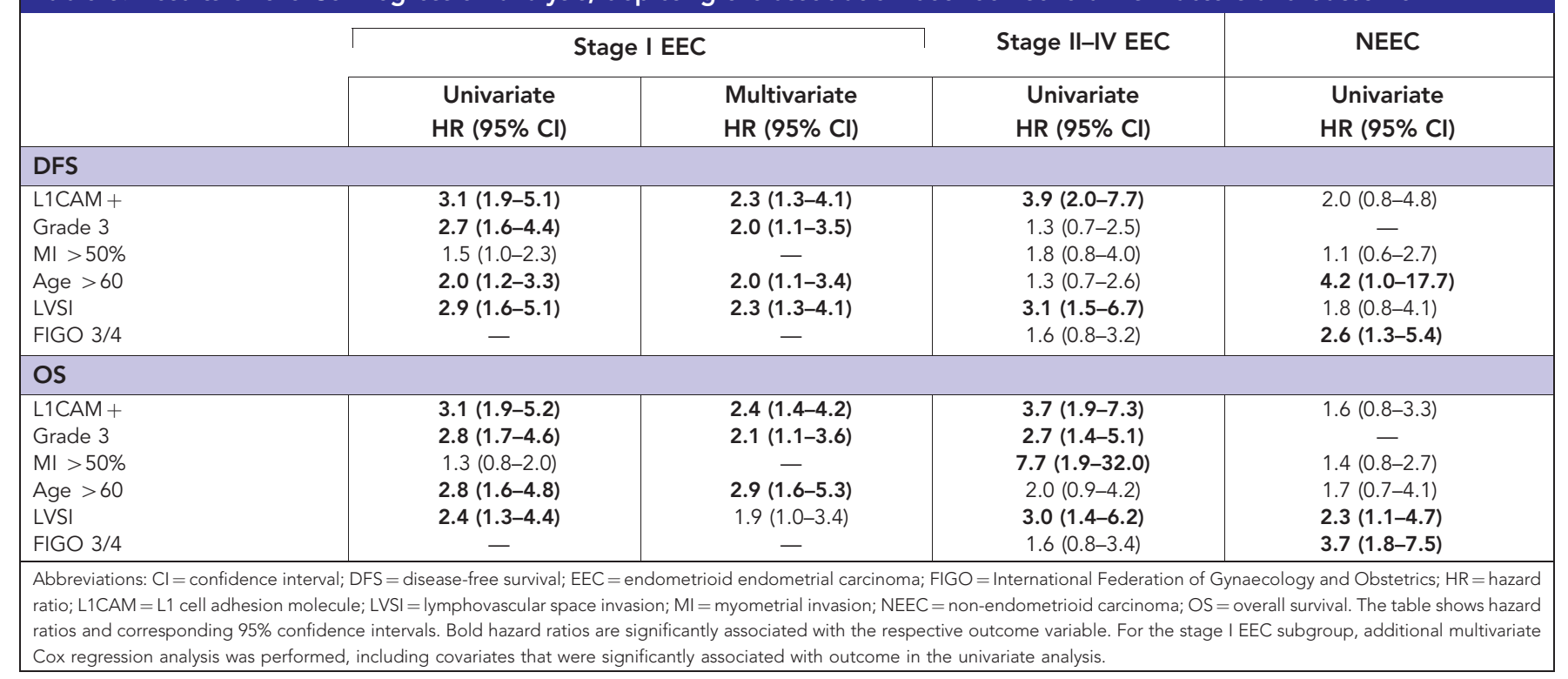

Future perspectives. Accumulating data associating L1CAM expression in stage I EECs with a poor outcome should have treatment implications. Moreover, this study shows that L1CAM expression in advanced-stage EECs is associated with poor outcome as well, and there was a trend towards more residual disease after treatment, in line with L1CAM expression in ovarian carcinoma that has been associated with restricted tumour resectability (Bondong et al, 2012). Although this would seem to support the use of chemotherapy, L1CAM expression in other cancer types has been shown to be associated with chemotherapy resistance (Sebens Muerkoster et al, 2007; Stoeck et al, 2007; Bondong et al, 2012). Given the fact that a substantial number of advanced-stage EECs and the majority of the NEECs are L1CAM positive, and a growing number of these carcinomas are treated with chemotherapy, studying the issue of resistance of L1CAMpositive tumours to chemotherapy has a high priority. In addition, the use of anti-L1CAM treatment might be an interesting future option (Knogler et al, 2007).

This study also found a strong association between L1CAM expression and the presence of other markers of poor prognosis, most notably non-endometrioid histology, grade 3 histology, and nodal disease. Once it is established that L1CAM expression in preoperative biopsies is in accordance with final pathology, incorporation into currently used preoperative prediction models might improve the selection of patients requiring a lymphadenectomy, and help pathologists to identify high-risk carcinomas, especially those with non-endometrioid histology.

In light of the recently proposed subdivision of endometrial carcinomas into four subgroups based on the molecular profile, it would be interesting to analyse the L1CAM expression in these four groups (Cancer Genome Atlas Research Network et al, 2013). The studies of both Dellinger et al (2016) and Van Gool et al 
(2016) looked at L1CAM expression in the mRNA data from the TGCA database, but unfortunately they did not describe the expression of L1CAM relative to the four proposed subgroups. If either L1CAM expression or the proposed genetic subdivision are to be used in the future management of endometrial carcinomas, it is imperative to know how these markers are related to each other.

Strengths and weaknesses. This is the largest study to date including all endometrial carcinoma types. Complete surgical staging was performed in the majority of cases, limiting the risk of under diagnosis, and a minimal follow-up of 36 months was required, limiting the risk of missing disease recurrences and deaths. As this was a retrospective study, there has been no standardised treatment protocol, and there is the risk for selection bias. There was no centralised pathology review in this study, but all slides were from large referral hospitals with dedicated gynaecological pathologists. This makes the results of this study applicable to daily practice in such hospitals.

\section{CONCLUSION}

In conclusion, this study shows the prognostic value of L1CAM expression in stage I EECs and advanced-stage EECs, but not in NEECs. The expression of L1CAM was associated with the presence of nodal disease, non-endometrioid histology, grade 3 histology, LVSI, and with a high risk of distant disease recurrence. Implementation of L1CAM expression in clinical practice could improve the postoperative selection of high-risk carcinomas. Both the value of L1CAM expression in the preoperative selection of high-risk carcinomas and the consequences of L1CAM expression on the use of and response to chemotherapy should be studied.

\section{CONFLICT OF INTEREST}

The authors declare no conflict of interest.

\section{REFERENCES}

Allory Y, Matsuoka Y, Bazille C, Christensen EI, Ronco P, Debiec H (2005) The L1 cell adhesion molecule is induced in renal cancer cells and correlates with metastasis in clear cell carcinomas. Clin Cancer Res 11(3): 1190-1197.

Amant F, Mirza MR, Koskas M, Creutzberg CL (2015) Cancer of the corpus uteri. Int J Gynaecol Obstet 131(Suppl 2): S96-104.

Bondong S, Kiefel H, Hielscher T, Zeimet AG, Zeillinger R, Pils D, Schuster E, Castillo-Tong DC, Cadron I, Vergote I, Braicu I, Sehouli J, Mahner S, Fogel M, Altevogt P (2012) Prognostic significance of L1CAM in ovarian cancer and its role in constitutive NF-kappaB activation. Ann Oncol 23(7): 1795-1802.

Boo YJ, Park JM, Kim J, Chae YS, Min BW, Um JW, Moon HY (2007) L1 expression as a marker for poor prognosis, tumor progression, and short survival in patients with colorectal cancer. Ann Surg Oncol 14(5): 1703-1711.

Bosse T, Nout RA, Stelloo E, Dreef E, Nijman HW, Jurgenliemk-Schulz IM, Jobsen JJ, Creutzberg CL, Smit VT (2014) L1 cell adhesion molecule is a strong predictor for distant recurrence and overall survival in early stage endometrial cancer: pooled PORTEC trial results. Eur J Cancer 50(15): 2602-2610.

Cancer Genome Atlas Research NetworkKandoth C, Schultz N, Cherniack AD, Akbani R, Liu Y, Shen H, Robertson AG, Pashtan I, Shen R, Benz CC, Yau C, Laird PW, Ding L, Zhang W, Mills GB, Kucherlapati R, Mardis ER, Levine DA (2013) Integrated genomic characterization of endometrial carcinoma. Nature 497(7447): 67-73.

Colas E, Pedrola N, Devis L, Ertekin T, Campoy I, Martinez E, Llaurado M, Rigau M, Olivan M, Garcia M, Cabrera S, Gil-Moreno A, Xercavins J, Castellvi J, Garcia A, Ramon y Cajal S, Moreno-Bueno G, Dolcet X,
Alameda F, Palacios J, Prat J, Doll A, Matias-Guiu X, Abal M, Reventos J (2012) The EMT signaling pathways in endometrial carcinoma Clin Transl Oncol 14(10): 715-720.

Dellinger TH, Smith DD, Ouyang C, Warden CD, Williams JC, Han ES (2016) L1CAM is an independent predictor of poor survival in endometrial cancer - an analysis of The Cancer Genome Atlas (TCGA). Gynecol Oncol 141(2): 336-340.

Engelsen IB, Stefansson I, Akslen LA, Salvesen HB (2006) Pathologic expression of p53 or p16 in preoperative curettage specimens identifies high-risk endometrial carcinomas. Am J Obstet Gynecol 195(4): 979-986. Fogel M, Gutwein P, Mechtersheimer S, Riedle S, Stoeck A, Smirnov A, Edler L, Ben-Arie A, Huszar M, Altevogt P (2003) L1 expression as a predictor of progression and survival in patients with uterine and ovarian carcinomas. Lancet 362(9387): 869-875.

Fogel M, Harari A, Muller-Holzner E, Zeimet AG, Moldenhauer G, Altevogt P (2014) A standardized staining protocol for L1CAM on formalin-fixed, paraffin-embedded tissues using automated platforms. Int J Biol Markers 29(2): e180-e183.

Friedli A, Fischer E, Novak-Hofer I, Cohrs S, Ballmer-Hofer K, Schubiger PA, Schibli R, Grunberg J (2009) The soluble form of the cancer-associated L1 cell adhesion molecule is a pro-angiogenic factor. Int J Biochem Cell Biol 41(7): 1572-1580.

Gast D, Riedle S, Issa Y, Pfeifer M, Beckhove P, Sanderson MP, Arlt M, Moldenhauer G, Fogel M, Kruger A, Altevogt P (2008a) The cytoplasmic part of L1-CAM controls growth and gene expression in human tumors that is reversed by therapeutic antibodies. Oncogene 27(9): 1281-1289.

Gast D, Riedle S, Kiefel H, Muerkoster SS, Schafer H, Schafer MK, Altevogt P (2008b) The RGD integrin binding site in human L1-CAM is important for nuclear signaling. Exp Cell Res 314(13): 2411-2418.

Gavert N, Ben-Shmuel A, Lemmon V, Brabletz T, Ben-Ze'ev A (2010) Nuclear factor-kappaB signaling and ezrin are essential for L1-mediated metastasis of colon cancer cells. J Cell Sci 123(Pt 12): 2135-2143.

Gavert N, Vivanti A, Hazin J, Brabletz T, Ben-Ze'ev A (2011) L1-mediated colon cancer cell metastasis does not require changes in EMT and cancer stem cell markers. Mol Cancer Res 9(1): 14-24.

Geels YP, Pijnenborg JM, Gordon BB, Fogel M, Altevogt P, Masadah R, Bulten J, van Kempen LC, Massuger LF (2016) L1CAM expression is related to nonendometrioid histology, and prognostic for poor outcome in endometrioid endometrial carcinoma. Pathol Oncol Res. e-pub ahead of print 18 February 2016.

Geismann C, Morscheck M, Koch D, Bergmann F, Ungefroren H, Arlt A, Tsao MS, Bachem MG, Altevogt P, Sipos B, Folsch UR, Schafer H, Muerkoster SS (2009) Up-regulation of L1CAM in pancreatic duct cells is transforming growth factor beta1- and slug-dependent: role in malignant transformation of pancreatic cancer. Cancer Res 69(10): $4517-4526$.

Huber MA, Azoitei N, Baumann B, Grunert S, Sommer A, Pehamberger H, Kraut N, Beug H, Wirth T (2004) NF-kappaB is essential for epithelialmesenchymal transition and metastasis in a model of breast cancer progression. J Clin Invest 114(4): 569-581.

Huszar M, Pfeifer M, Schirmer U, Kiefel H, Konecny GE, Ben-Arie A, Edler L, Munch M, Muller-Holzner E, Jerabek-Klestil S, Abdel-Azim S, Marth C, Zeimet AG, Altevogt P, Fogel M (2010) Up-regulation of L1CAM is linked to loss of hormone receptors and E-cadherin in aggressive subtypes of endometrial carcinomas. J Pathol 220(5): 551-561.

Kiefel H, Bondong S, Pfeifer M, Schirmer U, Erbe-Hoffmann N, Schafer H, Sebens S, Altevogt P (2012) EMT-associated up-regulation of L1CAM provides insights into L1CAM-mediated integrin signalling and NFkappaB activation. Carcinogenesis 33(10): 1919-1929.

Knogler K, Grunberg J, Zimmermann K, Cohrs S, Honer M, Ametamey S, Altevogt P, Fogel M, Schubiger PA, Novak-Hofer I (2007) Copper-67 radioimmunotherapy and growth inhibition by anti-L1-cell adhesion molecule monoclonal antibodies in a therapy model of ovarian cancer metastasis. Clin Cancer Res 13(2 Pt 1): 603-611.

Lax SF (2004) Molecular genetic pathways in various types of endometrial carcinoma: from a phenotypical to a molecular-based classification. Virchows Arch 444(3): 213-223.

Matias-Guiu X, Prat J (2013) Molecular pathology of endometrial carcinoma. Histopathology 62(1): 111-123.

Mechtersheimer S, Gutwein P, Agmon-Levin N, Stoeck A, Oleszewski M, Riedle S, Postina R, Fahrenholz F, Fogel M, Lemmon V, Altevogt P (2001) Ectodomain shedding of L1 adhesion molecule promotes 
cell migration by autocrine binding to integrins. J Cell Biol 155(4): 661-673.

Schafer MK, Frotscher M (2012) Role of L1CAM for axon sprouting and branching. Cell Tissue Res 349(1): 39-48.

Schroder C, Schumacher U, Fogel M, Feuerhake F, Muller V, Wirtz RM, Altevogt P, Krenkel S, Janicke F, Milde-Langosch K (2009) Expression and prognostic value of L1-CAM in breast cancer. Oncol Rep 22(5): 1109-1117.

Sebens Muerkoster S, Werbing V, Sipos B, Debus MA, Witt M, Grossmann M, Leisner D, Kotteritzsch J, Kappes H, Kloppel G, Altevogt P, Folsch UR, Schafer H (2007) Drug-induced expression of the cellular adhesion molecule L1CAM confers anti-apoptotic protection and chemoresistance in pancreatic ductal adenocarcinoma cells. Oncogene 26(19): 2759-2768.

Shtutman M, Levina E, Ohouo P, Baig M, Roninson IB (2006) Cell adhesion molecule L1 disrupts E-cadherin-containing adherens junctions and increases scattering and motility of MCF7 breast carcinoma cells. Cancer Res 66(23): 11370-11380.

Siegel R, Naishadham D, Jemal A (2012) Cancer statistics, 2012. CA Cancer J Clin 62(1): 10-29.

Stoeck A, Gast D, Sanderson MP, Issa Y, Gutwein P, Altevogt P (2007) L1-CAM in a membrane-bound or soluble form augments protection from apoptosis in ovarian carcinoma cells. Gynecol Oncol 104(2): 461-469.

Tischler V, Pfeifer M, Hausladen S, Schirmer U, Bonde AK, Kristiansen G, Sos ML, Weder W, Moch H, Altevogt P, Soltermann A (2011) L1CAM protein expression is associated with poor prognosis in non-small cell lung cancer. Mol Cancer 10: 127.
Tsutsumi S, Morohashi S, Kudo Y, Akasaka H, Ogasawara H, Ono M, Takasugi K, Ishido K, Hakamada K, Kijima H (2011) L1 Cell adhesion molecule (L1CAM) expression at the cancer invasive front is a novel prognostic marker of pancreatic ductal adenocarcinoma. J Surg Oncol 103(7): 669-673.

Van Gool IC, Stelloo E, Nout RA, Nijman HW, Edmondson RJ, Church DN, MacKay HJ, Leary A, Powell ME, Mileshkin L, Creutzberg CL, Smit VT, Bosse T (2016) Prognostic significance of L1CAM expression and its association with mutant p53 expression in high-risk endometrial cancer. Mod Pathol 29(2): 174-181.

Wang YY, Li L, Zhao ZS, Wang YX, Ye ZY, Tao HQ (2013) L1 and epithelial cell adhesion molecules associated with gastric cancer progression and prognosis in examination of specimens from 601 patients. J Exp Clin Cancer Res 32: 66.

Zeimet AG, Reimer D, Huszar M, Winterhoff B, Puistola U, Azim SA, MullerHolzner E, Ben-Arie A, van Kempen LC, Petru E, Jahn S, Geels YP, Massuger LF, Amant F, Polterauer S, Lappi-Blanco E, Bulten J, Meuter A, Tanouye S, Oppelt P, Stroh-Weigert M, Reinthaller A, Mariani A, Hackl W, Netzer M, Schirmer U, Vergote I, Altevogt P, Marth C, Fogel M (2013) L1CAM in early-stage type I endometrial cancer: results of a large multicenter evaluation. J Natl Cancer Inst 105(15): 1142-1150.

This work is published under the standard license to publish agreement. After 12 months the work will become freely available and the license terms will switch to a Creative Commons AttributionNonCommercial-Share Alike 4.0 Unported License.

\footnotetext{
${ }^{1}$ Department of Obstetrics and Gynaecology, Radboud University Medical Center, Geert Grooteplein 10, Nijmegen 6525GA, The Netherlands; ${ }^{2}$ Department of Pathology, Radboud University Medical Center, Geert Grooteplein 10, Nijmegen 6525GA, The Netherlands; ${ }^{3}$ Department of Pathology, Anthoni van Leeuwenhoek Hospital, Plesmanlaan 121, Amsterdam 1066CX, The Netherlands; ${ }^{4}$ Department of Pathology and Molecular Genetics and Research Laboratory, Hospital Universitari Arnau de Vilanova, University of Lleida, IRBLLEIDA, Avenida Alcalde Rovira Roure, 80, Lleida 25198, Spain; ${ }^{5}$ Institute of Pathology, University Medical Center Freiburg, Hugstetter Strasse 55, Freiburg 79106, Germany; ${ }^{6}$ Department of Obstetrics and Gynecology, University Medical Center Freiburg, Hugstetter Strasse 55, Freiburg 79106, Germany; ${ }^{7}$ German Cancer Consortium (DKTK), German Cancer Research Center (DKFZ), Im Neuenheimer Feld 280, Heidelberg D-69120, Germany; ${ }^{8}$ Biomedical Research Group in Gynecology, Vall Hebron Institute of Research (VHIR), Universitat Autònoma de Barcelona, Passeig de la Vall d'Hebron, 119-129, Barcelona 08035, Spain; 'Gynecological Department, Vall Hebron University Hospital, Passeig de la Vall d'Hebron, 119-129, Barcelona 08035, Spain; ${ }^{10}$ Department of Pathology, Vall Hebron University Hospital, Passeig de la Vall d'Hebron, 119-129, Barcelona 08035, Spain; ${ }^{11}$ Department of Obstetrics and Gynecology, Hospital del Mar, Passeig Marítim, 25-29, Barcelona 08003, Spain; ${ }^{12}$ Department of Pathology, Hospital del Mar, Passeig Marítim, 25-29, Barcelona 08003, Spain; ${ }^{13}$ Department of Obstetrics and Gynecology, Haukeland University Hospital, Jonas Lies vei 65, Bergen 5021, Norway; ${ }^{14}$ Department of Clinical Science, University of Bergen, PO Box 7800, Bergen 5020, Norway; ${ }^{15}$ Center for Cancer Biomarkers (CCBIO), University of Bergen, PO Box 7800, Bergen 5020, Norway; ${ }^{16}$ Department of Pathology, University of Turku, PO Box 7245, Laskut, Turku 01051, Finland; ${ }^{17}$ Department of Obstetrics and Gynecology, Division of Gynecologic Oncology, University Hospital Gasthuisberg, Herestraat 49, Leuven 3000, Belgium; ${ }^{18}$ Department of Obstetrics and Gynecology, Bichat-Claude Bernard Hospital, 46 Rue Henri Huchard, Paris 75018, France; ${ }^{19}$ Department of Pathology, Bichat-Claude Bernard Hospital, 46 Rue Henri Huchard, Paris 75018, France; ${ }^{20}$ Department of Gynecology and Obstetrics, Faculty of Medicine, Masaryk University, Kamenice 5, Brno 625 00, Czech Republic; ${ }^{21}$ Institute of Pathology, Faculty of Medicine, Masaryk University, Kamenice 5, Brno 625 00, Czech Republic; ${ }^{22}$ Department of Obstetrics and Gynaecology, Canisius-Wilhelmina Hospital, Weg door Jonkerbos 100, Nijmegen 6532SZ, The Netherlands; ${ }^{23}$ Department of Pathology, Canisius-Wilhelmina Hospital, Weg door Jonkerbos 100, Nijmegen 6532SZ, The Netherlands and ${ }^{24}$ Department of Obstetrics and Gynaecology, TweeSteden Hospital, Doctor Deelenlaan 5, Tilburg 5042AD, The Netherlands
} 